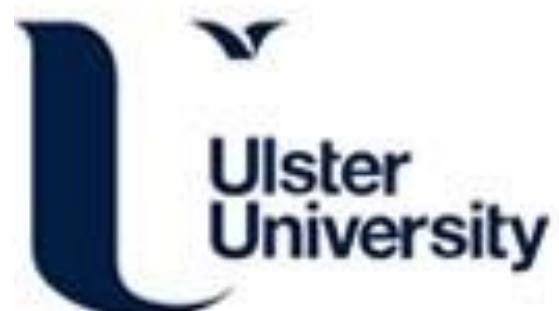

\section{Engaging students as partners in developing online learning and feedback activities for first year fluid mechanics}

Brown, A. (2018). Engaging students as partners in developing online learning and feedback activities for first year fluid mechanics. European Journal of Engineering Education, 43(1), 26-39.

https://doi.org/10.1080/03043797.2016.1232372

Link to publication record in Ulster University Research Portal

Published in:

European Journal of Engineering Education

Publication Status:

Published (in print/issue): 01/01/2018

DOI:

10.1080/03043797.2016.1232372

\section{Document Version}

Author Accepted version

\section{General rights}

Copyright for the publications made accessible via Ulster University's Research Portal is retained by the author(s) and / or other copyright owners and it is a condition of accessing these publications that users recognise and abide by the legal requirements associated with these rights.

\section{Take down policy}

The Research Portal is Ulster University's institutional repository that provides access to Ulster's research outputs. Every effort has been made to ensure that content in the Research Portal does not infringe any person's rights, or applicable UK laws. If you discover content in the Research Portal that you believe breaches copyright or violates any law, please contact pure-support@ulster.ac.uk. 
Engaging students as partners in developing online learning and feedback activities for first year fluid mechanics

Alan Brown

School of Engineering, Ulster University

Shore Road

Newtownabbey

BT37 0QB

UK

a.brown@ulster.ac.uk

$+442890368814$ 


\section{Abstract}

Much learning takes place outside of formal class settings, yet students starting in higher education are not always well equipped with independent learning skills, appropriate self-knowledge or the required levels of intrinsic motivation This project used students as partners to develop resources that could be used by first year undergraduates in fluid mechanics, using activities and receiving feedback through the VLE, in order to build these three attributes of independent learners While there were significant benefits to the students who developed the resources, the target students saw much lower benefits as a result of poorer than expected engagement.. The challenge this research presents is to develop activities that maximise engagement in large classes, as well as develop appropriate independent learning skills. 


\section{Introduction}

Fluid Mechanics is often found difficult by new engineering students (Bullen and Russell 2007). It has typically not been covered at all by students entering from school and has often received little coverage by students entering from Further Education. As a subject it also contains a range of key threshold concepts (Holloway, Alpay, and Bull 2010; Olakanmi and Doyoyo 2014) and common misconceptions (Streveler et al. 2008) that need to be understood and corrected if successful learning is to be achieved. If these concepts are not effectively learned and the misconceptions are not corrected at an early stage, then students find it difficult to be successful in this subject. Assessment tasks in fluid mechanics often take the form of unseen problems that evaluate the students' problem solving skills, in the context of their understanding of concepts. It is important that both the problem solving skills and the underlying concepts are both developed and assessed to ensure that effective engineering skills are developed. This research evaluates a range of novel independent learning activities, mostly generated by students, and associated feedback, and their effects on student engagement and performance.

Independent learning activities, such as weekly tutorial problems, form a large part of fluid mechanics teaching. Efforts have been made to increase engagement with independent learning, sometimes by awarding credit for completion of tutorial questions (Russell and Bullen 2005), or by using adaptive tutorials (Prusty and Russell 2011).Students are clearly motivated by activities that are associated with marks, but some evidence suggests that the availability of marks also encourages students to prioritise marks over learning by taking short cuts (Bullen and Russell 2007). Intrinsic motivation can be reduced by the inappropriate use of rewards (Vansteenkiste, Lens, and Deci 2006), and it is therefore important to encourage learners to engage with learning, not just with the gaining of marks. Methods such as Constructive Alignment (Biggs 2011) where assessments are aligned to accurately assess 
the true learning objectives, encourage the alignment of strategic learning or extrinsically motivated learning with the desired learning objectives. Care must be taken to not lessen the intrinsic motivation of students by focusing on assessment.

Students who are making the transition from school to Higher Education often do not always have effective independent learning skills, strategies and techniques (Jacob, Lee, and Lueckenhausen 2009). Research into study skills has shown some methods to be more effective than others for learning (Dunlosky et al. 2013). Two methods that have been shown to be effective in independent study, for learning both factual knowledge and new concepts or ideas, are Elaborative Interrogation (McDaniel and Donnelly 1996; Martin and Pressley 1991) and periodic testing (Rahman 2016).

Learning activities other than typical unseen problems are also important, both for developing conceptual knowledge and also for building reflective learning practice (McLaren, Lim, and Koedinger 2008). Concept inventories and specific concept questions (Streveler et al. 2008) have been widely used to ensure that students grasp the important fundamental concepts, as well as developing the applied mathematics skills that are required to apply those concepts (Olivero 2011). Without a good understanding of the threshold concepts in fluid mechanics, as in other mechanics subjects, the learner often resorts to a strategy of learning procedural methods that produce the "right answer" to a particular type of problem. This can result in a level of assessment success, but results in poor transfer, with the student having difficulty in applying their procedural knowledge consistently to unseen problems (Ron, Dreyfus, and Hershkowitz 2010) .

Independent learning activities should therefore be varied (McLaren, Lim, and Koedinger 2008; Olivero 2011). They should include unseen problems that demonstrate understanding, transfer and applied mathematical skills. They should also include concept questions, which require the student to think through a scenario and come up with the most 
likely outcome based on their understanding, and they should include learning centred activities which help the learner develop their learning skills and techniques, as well as their subject knowledge (Streveler et al. 2008). While some activities might have elements of reward associated with them in terms of marks or other credits, it is important that learners are able to undertake activities where the goal is learning, not just attaining marks (Alpay et al. 2010), especially in the transition from a more scaffolded school experience to a more independent experience in higher education.

One of the most important aspects of learning and feedback, is to be able to assess one's own knowledge and understanding. Self-knowledge and the connected idea of selffeedback are key elements of most successful learning strategies (Kruger and Dunning 1999; Kirschner and van Merriënboer 2013). A successful feedback strategy must balance the needs for specific, concrete feedback that will enable performance improvement in the context of the assessments that are being undertaken and the need for reflective practice that that enables learners to begin to evaluate their own knowledge and learning (Kirschner and van Merriënboer 2013; Prusty and Russell 2011, Huxham 2007, )). The development of these complex self-feedback strategies is a major task facing course and module developers.

Experienced students are very aware of the need to develop independence, and are more aware of the benefits of developing good habits of engagement and reflection. Engaging students as partners in course development (Power and Dunphy 2010; Duah and Croft 2012; Muñoz-García et al. 2013) allows these students to both enhance the course, making it more relevant and better suited to the students, and also significantly benefits the partner students, as they are able to stretch themselves, gaining more independent learning skills by thinking about the same threshold concepts that they have previously learned (Bovill, Cook-Sather, and Felten 2011; Willey and Gardner 2010). 
It is clear then that self-feedback and independent learning skills need to be developed, and it is the role of educators to help students learn these skills as well as learn the technical content of fluid mechanics. There are three areas in which this research aims to contribute to this area. Firstly, by combining traditional unseen tutorial problems with activities that develop and evaluate conceptual understanding, it is hoped that students will experience new, effective learning techniques that they can apply to other areas of study. Secondly, by providing additional resources that are not compulsory, it should be possible to evaluate and encourage students' intrinsic motivation and engagement, and discourage shortcuts that may reduce the opportunity for deeper learning. Finally, by including rapid, automated feedback, it is intended that improvements in metacognition, or in self- or peerfeedback can be made This paper therefore, describes the process by which a suite of independent learning activities were produced for an introductory module on fluid mechanics. Activities were developed by more experienced students and others by academic staff, and were delivered largely through a VLE. The paper also describes the levels of engagement with these activities, and the outcomes in terms of module performance and student experience. The module performance and experience of the partner students has also been evaluated.

\section{Methodology}

Prior to commencement of this research, the study design was submitted to the Faculty Ethics filter committee for approval. Participation in the study was voluntary, and all data were stored and analysed according to University guidelines.

This project was directed at improving an introductory course in fluid mechanics. This course is taken by first year Bachelor of Engineering students, primarily in Mechanical Engineering. The enrolment in the year of this study was 99 students. One lecture per week 
covers the concepts to be covered, and a second lecture focuses on solving worked example problems from the weekly problem sheets. The weekly tutorial sessions facilitate both group and individual support on completing the weekly problem sheets. The fluid mechanics course starts with the basic definitions of fluid, pressure, density and viscosity, then covers fluid statics with an introduction to pressure at a depth, buoyancy and some basic hydraulics and finishes with fluid dynamics, covering continuity of flow (mass balance), Bernoulli's equation (energy balance) and fluid kinematics including an introduction to laminar and turbulent flow and some flow visualisation methods. This introductory module is followed up by more advanced modules in both second year and final year of the Mechanical Engineering programme.

\subsection{Resource Development}

\section{Concept Questions}

In order to promote self-knowledge, and regular self-testing (Dunlosky et al. 2013), this introductory fluid mechanics module has been developed with a series of multiple choice concept quizzes throughout, developed by academic staff.. Brief feedback is provided with these quizzes, with the intention of informing students of what they understand or don't understand. The quizzes are delivered via the VLE and are linked with the other learning materials (lecture slides and problem sheets) using the adaptive release feature of the VLE. Lecture and tutorial materials are not visible to students until they have attempted the quiz each week. No marks are assigned and students can attempt the quizzes as many times as they wish. A screenshot of a typical MQC is shown in Figure 1.

\section{Resources developed by students as partners}

All eight partner students were volunteers. The first four students to volunteer from year 2 
and the first four from final year were selected. There was a range of abilities within the group of volunteers as measured by their previous marks in fluid mechanics. The performances of the year 2 students in a previous fluid mechanics module were $40 \%, 43 \%$, $56 \%$ and $63 \%$, against a class average of $54 \%$ overall. The final year students previous fluid mechanics marks were $40 \%, 54 \%, 59 \%$ and $83 \%$, against a class average of $46 \%$ overall.

The group of eight students were introduced to two specific learning activities and tasked with developing resources that would use these techniques. Of the eight students, two were only able to attend two of the sessions, but the remaining six attended all four sessions. Session one introduced elaborative interrogation (EI) (McDaniel and Donnelly 1996) and each student selected a piece of text and wrote three or four questions and model answers. In session two, these text book sections were scanned and the activities written on the VLE.

On answering the questions, students are provided with a brief discussion on the question, which should inform their opinion on the topic, and clarify any misunderstandings they may have. Figure 2 shows a screenshot of a typical EI activity.

In session three, students were instructed on how to select questions for practice question (PQ) activities (Rahman 2016), and then selected a range of appropriate questions, some at an introductory level, and others at a more advanced level. Students worked in pairs for this activity. In the final session, the practice tests were developed as Blackboard quizzes, with the correct answer being given as the minimum feedback. More typically a number of prompts that should help the student reach the solution were given as feedback, as well as the correct answer. Figure 3 shows a typical PQ activity, developed by the partner students. 


\subsection{Implementation}

The learning activities were implemented via the VLE. For the elaborative interrogation questions, the passage of text chosen by the students was scanned and provided along with the sample questions. Students using the activities were also encouraged to ask their own questions. The emphasis of these questions is not to create a perfect answer, but to help students to learn the concepts by asking and answering 'why?' questions. By answering based on prior knowledge and understanding, it is anticipated that associating these concepts with ideas already understood, that both recall and genuine understanding will be improved (Dunlosky et al. 2013). These learning activities were provided on the VLE, along with the lecture materials and traditional problem sheets that are provided each week.

The practice tests were also delivered using the VLE. These were set up as quizzes, with a range of multiple choice and calculated questions. In structure these are similar to the problem sheets, but in these cases, answers and feedback were automated and therefore immediate. Some of the partner students provided rich feedback with their practice questions, including comments on what common mistakes might be. Others provided the correct answer, with little additional information. Some of the practice quizzes were straightforward and some were more advanced. This was intended to provide a range of activities for students with a range of abilities and background knowledge.

From the start of the year 1 module, all of the activities prepared by the student partners were entirely optional. They were provided as additional work that was intended to improve students understanding. No marks were allocated for the completion of any of the tasks, and they were introduced during timetabled lecture and tutorial sessions as additional resources that were there for the benefit of students. The multiple choice quizzes had to be attempted to release the rest of the VLE materials, but if students did not wish to engage with these quizzes, they were at liberty to answer the questions without thought. There was no 
penalty for this, but also no opportunity for learning. By keeping the activities as optional, it was hoped that students' motivation would be driven intrinsically by the learning opportunity, rather than extrinsically by a sense of compulsion or to gain marks. The importance of intrinsic motivation to deep learning remains part of the ethos of the teaching team on this module (Vansteenkiste, Lens, and Deci 2006).

\subsection{Evaluation}

Evaluation was largely of two types. Firstly, data gathered from the VLE as well as via attendance monitoring and assessment performance was used to evaluate the effectiveness of the various learning activities on the performance of students. Secondly, students' opinions on the different learning activities were ascertained using an anonymous survey. The specific measures that were considered were module attendance, engagement with the various VLE activities, including multiple choice concept quizzes (MCQ), Elaborative Interrogation (EI) and Practice Tests (PT), as well as performance indicators such as class test performance, exam performance and overall module performance.

Both the partner students, who developed the materials and the year 1 students who were the intended users of these materials were surveyed, and the performance of both groups evaluated as part of normal learning and teaching practice and also specifically for this study. The survey was optional and anonymous, and in it students were presented with statements about their experience of the module, and were asked to state their level of agreement with these statements using Likert-scales. Most statements were related to the online learning activities. Examples of these statements are:

\footnotetext{
"The multiple choice quizzes help me to understand the material that is taught each week."
} 
"For the activities that were provided that were reading and Understanding activities (Using Elaborative Interrogation), please indicate the extent to which you agree with the following statement:

- Having to describe concepts in my own words was difficult

- The reading and understanding activities helped me to remember concepts"

The Likert-scale questions were also supplemented with free-form text answers on one thing that was done well on the module and one thing that they feel could be improved.

\section{Results}

\subsection{Partner Student Performance and Experiences}

The eight partner students' performance was clearly improved after their engagement with fluid mechanics. Of the year 2 students, three improved their marks significantly over their year 1 performance. The average mark for the four students increasing from $50 \%$ to $62 \%$. This is in contrast to the overall class average which went down from $54 \%$ to $47 \%$, a downward trend which is commonly observed between year 1 and year 2 . When seen in this context, the students who acted as partners clearly outperformed their peers.

For the final year cohort, the class average increased from $46 \%$ to $71 \%$ in fluid mechanics. For the student partners, all of them performed significantly better than the class average, with marks of $79 \%, 85 \%, 85 \%$ and $95 \%$ in the fluid mechanics elements.

The partner students gave some positive feedback on the process of preparing resources, some of which are shown below:

\footnotetext{
"Students can steer the lecturer in the right direction"

"I found (elaborative interrogation) very beneficial and use it in my own studies"

"I like the stop start approach, checking your own answers"
} 
From these responses, some of the objectives of this project can be observed. One student has learned a new technique (EI) and is using it on other studies. Another has expressed that the ability to check your answers regularly is helpful, hopefully also improving metacognition.

\subsection{Target student engagement}

Engagement with the VLE based learning activities was lower than expected. Of the three different types of activities, MCQs had the highest engagement, with each student using MCQs an average of five times. EI activities were used an average of 1.4 times per student and the practice tests an average of 1.0 times per student. This means that the majority of students did not engage with most of these activities during the course of the module.

.Figure 4 shows histograms of the levels of engagement with these three different types of online learning activities. It can be clearly seen that there are a large group of students who did not engage with the EI activities and also with the PQ activities.

\subsection{Target student module performance}

For the overall module, the mean mark was $50.4 \%$. This compares with a mean mark in other modules in year 1 in semester 1 of $62 \%$. Fluid mechanics, along with mechanical science subjects typically see lower marks than some of the other year 1 modules. The four year average mark for this module is $50.3 \%$, suggesting that this cohort is not atypical.

In order to identify the important factors that might help to predict student success, and likewise flag students at risk of failure, Pearson's correlations were determined, these can be seen for a number of key parameters in Table 1. When considering individual student performance in the module, engagement with the independent learning activities was 
compared with the overall module performance. It was found that both MCQ attempts and attendance were correlated with overall module performance at the $\mathrm{p}<0.01$ level, but that the correlation shows a larger effect for MCQ engagement than for Attendance. It is believed that both Attendance and MCQ attempts are measures of engagement, and this result suggests that engagement with the online materials is perhaps a better measure of effective engagement than attending class. With conceptually difficult material and with mathematical problem solving, much of the learning must occur during independent study. Listening, following and taking notes in lectures and engaging with tutorials may give the impression of learning, but real understanding must remain when the support of teaching staff is not present, such as is the case during an examination.

There is a weaker correlation between the engagement with PQ activities and module success $(\mathrm{p}<0.05)$ than with the MCQ activities, a result of the significantly lower number of students who engaged meaningfully with these activities.

Considering the MCQs as a measure of engagement, students in the lower quartile, who completed four or fewer MCQs averaged $42.5 \%$ overall, with $36 \%$ of these students failing the module at the first attempt, while those in the upper quartile who completed more than seven MCQs averaged $63.3 \%$, with $7 \%$ failing the module at the first attempt. In the inter-quartile range, the mean mark was $49.4 \%$, and $12 \%$ of students failed the module at the first attempt.

To allow for different levels of ability, the mean mark that students had achieved in modules prior to this module was considered. Students had previously studied modules in Mathematics, Engineering Design and Materials. The average mark was $61.9 \%$, with the lower quartile at $52.8 \%$ and the upper quartile at $74.2 \%$. Previous marks were significantly correlated with the overall mark in the year 1 Fluid Mechanics module. 
Combining the best measure of engagement (Engagement with MCQs) with prior attainment (Average semester 1 mark), a linear regression model showed an adjusted $\mathrm{R}^{2}$ of 0.559 , with a standard error of 11.6, the equation for this linear regression is:

$$
\text { overallmark }=0.669(\text { Avg_S1_Mark })+2.802\left(M C Q \_ \text {all }\right)-7.303
$$

Figure 5 shows a 3D scatter plot showing the relationship between the overall mark, the MCQ engagement and the prior Semester 1 average mark, showing that the overall mark is influenced both by prior attainment and engagement.

\subsection{Student perception of the learning activities}

The results from the survey of student experience shows that students find the independent learning activities generally to be helpful. Figure 6 shows the responses to some of the questions asked. It is clear that feedback is valued by students, and that those who used the various online activities were much more likely to find them helpful than unhelpful. One interesting finding was that more of the students would not rather have lots of automated feedback, rather than a small amount of personal feedback.

The preference for personal feedback is one that is not unexpected, but it is interesting that the quantity of feedback may be less important to students than the manner in which it is delivered. The relationship between the impact of feedback on assessment performance and its impact on less quantifiable issues like confidence and motivation would be an interesting topic for further research.

In terms of the free-form responses to the student experience survey, while positive comments outweighed negative, it was clear that there were people for whom the activities worked well, and those who did not find them useful. The following two quotes concern the EI Activities: 
'It is clear what should be learned. EI technique is interesting and I believe it will be useful in helping me learn and connect different aspects of the course'

'The EI activities are not to my taste'

The Multiple Choice Quizzes received the most comments of all of the activities, most were positive, but there were some that found them to be less helpful:

'The MCQ are in my opinion the most useful aspect of learning in this course'

'The MCQs were done very well, allowing me to attempt to answer them correctly. If I did not, this made me question why I went for the answers I did.'

'Remove the tests that allow you to access the content. They are annoying and failed to load for me sometimes'

Overall, the student responses suggest that they would rather have more activities rather than fewer, and that most of the students found them helpful.

\section{Discussion and Implications for Learning and Teaching}

The results of this study can be divided into the effects on the partner students and the effects on the target students, and will be covered in the following sub-sections:

\subsection{Effects on partner students}

One of the clearest findings of this research is that the main beneficiaries of the learning resources appear to have been the partner students, who developed the resources, rather than those for whom the learning activities have been prepared. While these students were 
volunteers, and thus were self-selecting and motivated, they had not all previously shown high levels of performance in this topic. It is well known that teaching something often deepens ones understanding (Whitman and Fife 1988), and this is borne out by the performance of these students. Those in year 2 , who had only recently completed the same year1 module for which they were writing resources, made significant improvements on their marks, suggesting a much improved understanding of the basic concepts in fluid mechanics. In order to prepare EI activities, partner students had to read multiple texts, choose the one that they felt was most appropriate and devise some 'why?' questions. They also had to answer the same 'why?' questions. In the PQ activities, partner students had to formulate a quiz using questions from the course text book, and provide feedback for both the correct and the common incorrect answers. In doing these preparation activities, partner students had to develop a much deeper understanding of the threshold concepts than they had previously developed by studying the module.

The benefits to the partner students of preparing material are to be expected and have been observed elsewhere (Bovill, Cook-Sather, and Felten 2011), more interesting are the implications of these findings for future module delivery. One option would be to increase the use of final year students as teaching assistants in lower level modules, but that will only impact the small numbers of partner students. Finding ways to incorporate this type of resource preparation activity into the standard module delivery is more of a challenge. Peer instruction is one way of delivering this type of activity, either using group discussion activities in large lectures (Deslauriers, Schelew, and Wieman 2011), or by using student-led recitations to replace some tutorials (Stock et al. 2013; Crawley et al. 2014, ). In addition, the incorporation of effective and specific study techniques within the wider curriculum has the potential to benefit students across different modules. 


\subsection{Effects on target students}

It was intended that all of the resources would have a significant effect on the ways in which students went about independent study, and that by teaching the techniques of EI and the use of regular self-testing using the MCQ and PQ activities, that some improvements to module outcomes would result. These improvements were not observed in this study. Overall module averages across the 99 students who took this module were within the normal range observed in this module in previous years. Engagement with the EI and PQ activities were much lower than expected. The purpose was to make these activities voluntary to try and promote some intrinsic motivation to learn, rather than use extrinsic motivations such as marks. It is clear that without some direct link to assessment that the majority of students in year 1 were not self-motivated enough to try these activities. Perhaps the process of transition to higher education requires a more extrinsic approach in order to develop the skills and to start to develop the intrinsic motivation in future years. It has been widely shown that assessment will to a significant extent direct activity (Biggs 2011; Russell 2005), but care must be taken to avoid opportunities for students to play the system, pursuing the benefits of marks without the costs of learning (Bullen and Russell 2007).

Engagement with the MCQ system was much more robust. The conditional release of next week's resources meant that students did engage with these questions to a much more significant extent. In terms of the relationship between engagement and module performance, attempting the MCQs had a stronger correlation with module success than attendance, suggesting that it could be an alternative measure of engagement than physical presence in class. With the push towards more online content in blended learning environments, the use of VLEs to monitor real-time student engagement is an area that should be investigated more fully. 
While the MCQs and the conditional release system showed significant benefits in terms of monitoring engagement, the nature of the questions and the fact that the answers to the questions are not used in any form of assessment means that the learning opportunity that these activities provide is limited. Students are only required to attempt the questions in order to access the next set of resources, rather than have to get the correct answer. As a result, student performance on these questions is not logged, and opportunities for clarification of misunderstandings are not then obvious. The system could be enhanced by having the MCQs linked more closely with assessment, and then used by staff to determine the effectiveness of teaching. Bringing these questions into the teaching sessions, using audience response systems for example (Deslauriers, Schelew, and Wieman 2011) might prove beneficial.

Finally, combining the EI and PQ activities with the MCQ system would be possible. By asking MCQs that relate directly to the other activities, it might be possible to encourage students to do more independent study, and in doing so, learn new techniques and improve their conceptual understanding. MCQs have also been used to encourage preparation for class, as well as just a review of past learning (Deslauriers, Schelew, and Wieman 2011), so a combination of review and preparation for class would be a promising opportunity to build on the success of the MCQs in terms of engagement, adding some more challenging learning activities at the same time.

With large class sizes, and complex material, it is imperative that new students learn the importance of putting independent time and effort into learning, understand the learning techniques that they have to use and are able to get feedback on what they are doing. This project aimed to evaluate and develop these three aspects of independent learning. Overall, the MCQ activities delivered via the VLE have been shown to be effective in terms of engagement, but the more involved activities, EI and PQ, have seen limited engagement. The overall performance on the module was correlated with engagement, but there was no 
significant improvement noted when compared with previous years. To ensure engagement with the majority of students, it is clear that there needs to be some sort of extrinsic incentive that communicates the value of the activity. As a result, it would be interesting to allocate a small number of marks to the EI and PQ activities, or use the adaptive release system.

Perhaps to make the MCQ activities more involved, and to design them so that students have to undertake the EI activities before they can answer the questions might improve engagement. Improved engagement should lead to improved learning, in terms of subject specific knowledge and skills, generic learning techniques and self-feedback.

Overall, this project has highlighted the need to consider multiple factors, such as motivation and engagement, learning techniques and metacognition in designing independent learning activities. It is clear that the link between incentives and engagement needs to be further studied in this context, in order to provide the appropriate environment to develop intrinsic motivation and independence, but using extrinsic incentives to drive initial engagement. Partner students, who were self-selecting and highly motivated showed much improved learning. The challenge is to extend these lessons to the wider group of students.

\section{Acknowledegments}

Some of this work was made possible by a Santander 100 scholarship, awarded in 2013 by Santander Bank, administered by the Centre for Higher Education Research and Practice at Ulster University. The author would also like to acknowledge the contributions of the eight partner students, Patrick Conway, Mark Cosby, Anthony Harkin, Catherine Kearney, Ryan McCormick, Pearse McGrath, Shauna Mullin and Andrew Russell. 


\section{References}

Alpay, Esat, PS Cutler, Susan Eisenbach, and AJ Field. 2010. "Changing the Marks-Based Culture of Learning through Peer-Assisted Tutorials." European Journal of Engineering Education 35 (1): 17-32.

Biggs, John B. 2011. Teaching for Quality Learning at University: What the Student Does McGraw-Hill Education (UK).

Bovill, Catherine, Alison Cook-Sather, and Peter Felten. 2011. "Students as Co-creators of Teaching Approaches, Course Design, and Curricula: Implications for Academic Developers." International Journal for Academic Development 16 (2): 133-145.

Bullen, Peter and Mark Russell. 2007. "A Blended Learning Approach to Teaching First Year Engineering Degree Students."Citeseer, .

Crawley, Edward F., Johan Malmqvist, Sören Östlund, Doris R. Brodeur, and Kristina Edström. 2014. "Teaching and Learning." In Rethinking Engineering Education, 143163: Springer.

Deslauriers, L., E. Schelew, and C. Wieman. 2011. "Improved Learning in a LargeEnrollment Physics Class." Science (New York, N.Y.) 332 (6031): 862-864.

Duah, Francis and Tony Croft. 2012. "Students as Partners in Mathematics Course Design." . Dunlosky, J., K. A. Rawson, E. J. Marsh, M. J. Nathan, and D. T. Willingham. 2013. "Improving Students' Learning with Effective Learning Techniques: Promising Directions from Cognitive and Educational Psychology." Psychological Science in the Public Interest : A Journal of the American Psychological Society 14 (1): 4-58. Holloway, M., E. Alpay, and A. Bull. 2010. "A Quantitative Approach to Identifying Threshold Concepts in Engineering Education."Higher Education Academy, . Huxham, Mark. 2007. "Fast and Effective Feedback: Are Model Answers the Answer?" Assessment \& Evaluation in Higher Education 32 (6): 601-611.

Jacob, Seibu Mary, Betsy Lee, and Gillian Rosemary Lueckenhausen. 2009. "Measuring Critical Thinking Skills in Engineering Mathematics using Online Forums."IEEE, . Kalyuga, Slava, Paul Chandler, Juhani Tuovinen, and John Sweller. 2001. "When Problem Solving is Superior to Studying Worked Examples." Journal of Educational Psychology 93 (3): 579.

Kirschner, Paul A. and Jeroen JG van Merriënboer. 2013. "Do Learners really Know Best? Urban Legends in Education." Educational Psychologist 48 (3): 169-183. 
Kruger, Justin and David Dunning. 1999. "Unskilled and Unaware of it: How Difficulties in Recognizing One's Own Incompetence Lead to Inflated Self-Assessments." Journal of Personality and Social Psychology 77 (6): 1121.

Martin, Vicky L. and Michael Pressley. 1991. "Elaborative-Interrogation Effects Depend on the Nature of the Question." Journal of Educational Psychology 83 (1): 113.

McDaniel, Mark A. and Carol M. Donnelly. 1996. "Learning with Analogy and Elaborative Interrogation." Journal of Educational Psychology 88 (3): 508.

McLaren, Bruce M., Sung-Joo Lim, and Kenneth R. Koedinger. 2008. "When and how often should Worked Examples be Given to Students? New Results and a Summary of the Current State of Research.".

Meyer, Jan HF, David B. Knight, David P. Callaghan, and Tom E. Baldock. 2015. "An Empirical Exploration of Metacognitive Assessment Activities in a Third-Year Civil Engineering Hydraulics Course." European Journal of Engineering Education 40 (3): 309-327.

Mourtos, Nikos J., N. DeJong-Okamoto, and Jinny Rhee. 2004. "Open-Ended ProblemSolving Skills in Thermal-Fluids Engineering." Global Journal of Engineering Education: 189.

Muñoz-García, Miguel A., Guillermo P. Moreda, Natalia Hernández-Sánchez, and Vanesa Valiño. 2013. "Student Reciprocal Peer Teaching as a Method for Active Learning: An Experience in an Electrotechnical Laboratory." Journal of Science Education and Technology 22 (5): 729-734.

Olakanmi, EO and M. Doyoyo. 2014. "Using Structured Examples and Prompting Reflective Questions to Correct Misconceptions about Thermodynamic Concepts." European Journal of Engineering Education 39 (2): 157-187.

Olivero, F. 2011. Innovative Pedagogical Scenarios for First Year Mechanics Students: Higher Education Academy.

Power, Clare and Kiyomi Dunphy. 2010. "Peer Facilitated Learning in Mathematics for Engineering: A Case Study from an Australian University." Engineering Education 5 (1): 75-84.

Prusty, B. Gangadhara and Carol Russell. 2011. "Engaging Students in Learning Threshold Concepts in Engineering Mechanics: Adaptive eLearning Tutorials.".

Rahman, Ataur. 2016. "A Blended Learning Approach to Teach Fluid Mechanics in Engineering." European Journal of Engineering Education: 1-8. 
Ron, Gila, Tommy Dreyfus, and Rina Hershkowitz. 2010. "Partially Correct Constructs Illuminate Students' Inconsistent Answers." Educational Studies in Mathematics 75 (1): 65-87.

Russell, M. and P. Bullen. 2005. Improving Student Success and Retention through Greated Participation and Tackling Student Unique Tutorial Sheets. York: Higher Education Academy.

Russell, Mark. 2005. "Evaluating the Weekly-Assessed Tutorial Sheet Approach to Assessment: Background, Pedagogy and Impact." Journal for the Enhancement of Learning and Teaching.

Stock, Wendy A., Kevin Ward, Justin Folsom, Teresa Borrenpohl, Sophie Mumford, Zach Pershin, Danielle Carriere, and Heather Smart. 2013. "Cheap and Effective: The Impact of Student-Led Recitation Classes on Learning Outcomes in Introductory Economics." The Journal of Economic Education 44 (1): 1-16.

Streveler, Ruth A., Thomas A. Litzinger, Ronald L. Miller, and Paul S. Steif. 2008. "Learning Conceptual Knowledge in the Engineering Sciences: Overview and Future Research Directions." Journal of Engineering Education 97 (3): 279-294.

Vansteenkiste, Maarten, Willy Lens, and Edward L. Deci. 2006. "Intrinsic Versus Extrinsic Goal Contents in Self-Determination Theory: Another Look at the Quality of Academic Motivation." Educational Psychologist 41 (1): 19-31.

Whitman, Neal A. and Jonathan D. Fife. 1988. Peer Teaching: To Teach is to Learn Twice. ASHE-ERIC Higher Education Report no. 4, 1988. ERIC.

Willey, Keith and Anne Gardner. 2010. "Investigating the Capacity of Self and Peer Assessment Activities to Engage Students and Promote Learning." European Journal of Engineering Education 35 (4): 429-443. 
Table 1: Pearson's correlations between the overall mark in the year 1 fluid mechanics module and some of the other measured parameters. Significant correlations can be seen with Attendance, engagement with MCQs and the average mark in semester 1 modules.

\begin{tabular}{lccc}
\hline & \multicolumn{2}{c}{ Overall Mark in year 1 fluid mechanics } \\
\hline Avg_S1_Mark & Pearson correlation & Significance & N \\
ATT_total & 0.658 & 0.000 & 82 \\
MCQ_all & 0.404 & 0.000 & 99 \\
EI_All & 0.516 & 0.000 & 99 \\
PQ_All & 0.178 & 0.078 & 99 \\
\hline
\end{tabular}




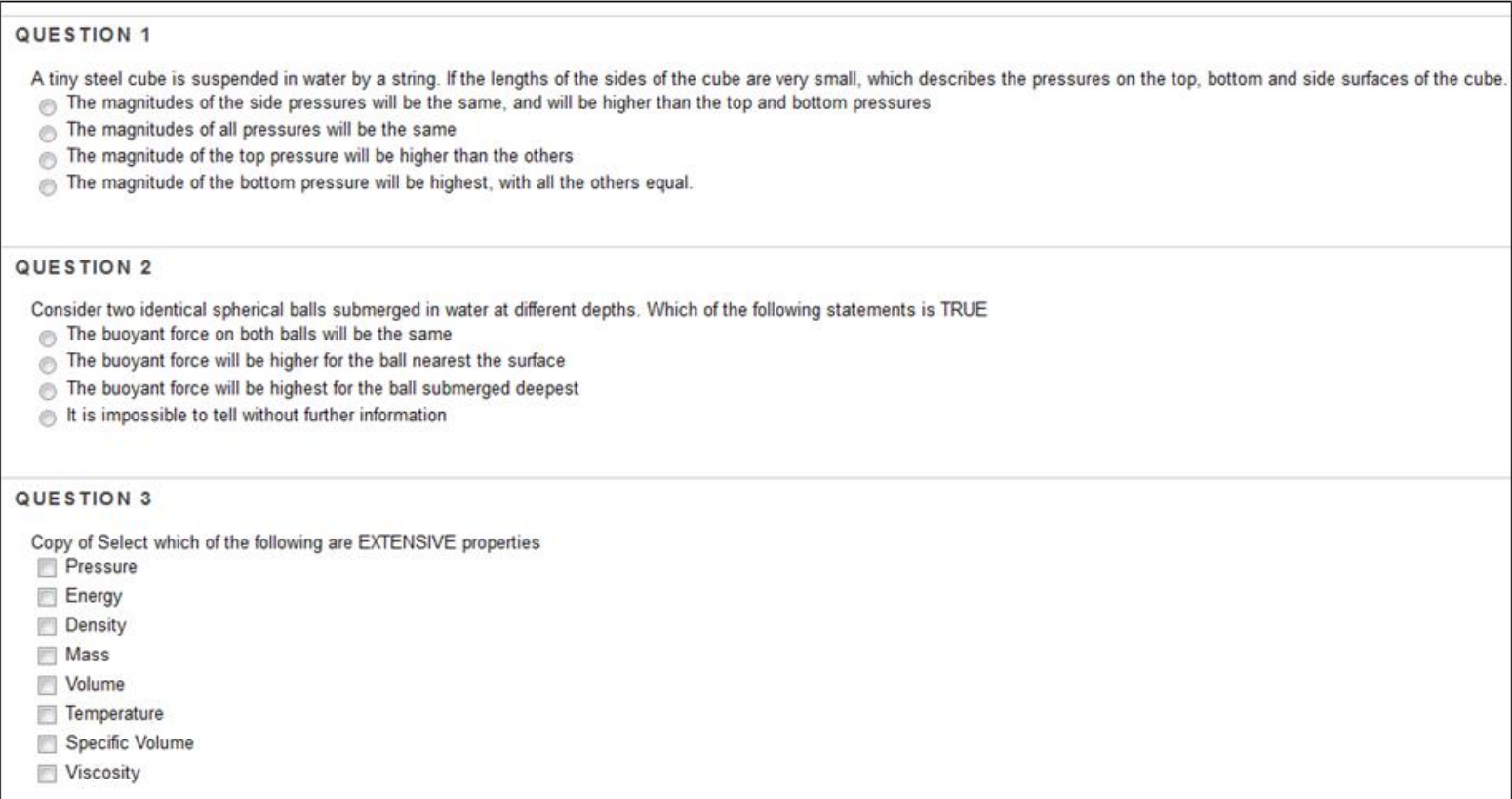

Figure 1: Screenshot of Multiple Choice Quiz (MCQ) delivered via Blackboard and linked to future lecture materials using the adaptive release function. 

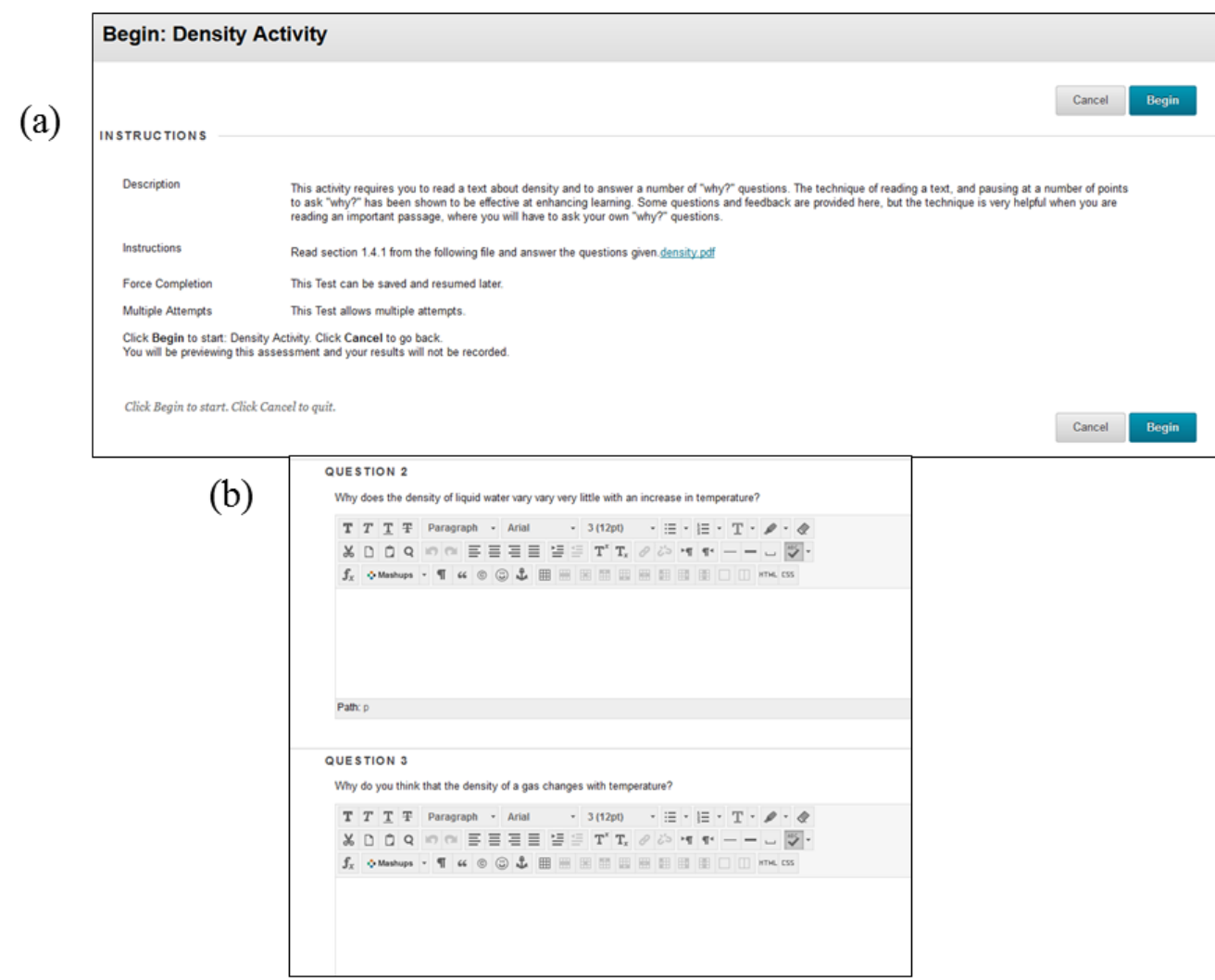

Figure 2: Screenshot showing example questions asked in the EI activity. (a) shows the introductory dialog that links to the text, taken from one of the set course texts in fluid mechanics. (b) shows the questions that the students are asked once they have read the text. 


\begin{tabular}{|c|c|}
\hline \multicolumn{2}{|l|}{ QUESTION 2} \\
\hline \multicolumn{2}{|c|}{ Q10-8 from Fundamentals of Thermal Fluid Sciences 3rd Edition: } \\
\hline \multicolumn{2}{|c|}{ Consider a $4 \mathrm{~m}$ long. $4 \mathrm{~m}$ wide and $1.5 \mathrm{~m}$ high above ground swimming pool filled with water to the rim. Determine the hydostatic force acting on each wall in kiloNewtons } \\
\hline \multicolumn{2}{|c|}{ The density of water can be taken as $1000 \mathrm{~kg} / \mathrm{m}^{3}$} \\
\hline \multicolumn{2}{|l|}{ QUESTION 3} \\
\hline \multicolumn{2}{|c|}{ For the same swimmiong pool as above, determine the distance of the line of action of the hydrostatic force from the ground, in metres } \\
\hline \multicolumn{2}{|l|}{ Question 2} \\
\hline \multicolumn{2}{|c|}{ Q10-8 from Fundamentals of Thermal Fluid Sciences 3rd Edition: } \\
\hline \multicolumn{2}{|r|}{ Consider a $4 \mathrm{~m}$ long. $4 \mathrm{~m}$ wide and $1.5 \mathrm{~m}$ high above ground swimming pool filled with water to the rim. Determine the hydostatic force acting on each wall in kiloNewtons } \\
\hline \multicolumn{2}{|c|}{ The density of water can be taken as $1000 \mathrm{~kg} / \mathrm{m}^{3}$} \\
\hline \multicolumn{2}{|l|}{ Selected Answer: 118} \\
\hline \multirow{2}{*}{\multicolumn{2}{|c|}{ Response Feedback: If you have 44100 , then you have calculated the force correctly, but in Nemtons }} \\
\hline & \\
\hline & Calculate the average pressure in the pool using pg(h/2) \\
\hline & This should be $7357.5{\mathrm{~N} / \mathrm{m}^{2}}^{2}$ \\
\hline & Atmospheric pressure acts on both sides of the wall \\
\hline
\end{tabular}

Figure 3: Screenshot showing (a) typical introductory practice questions and (b) the feedback that is provided after one of the questions is answered. 


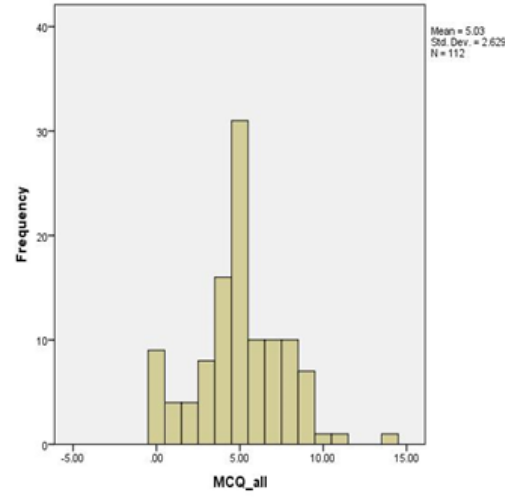

(a)

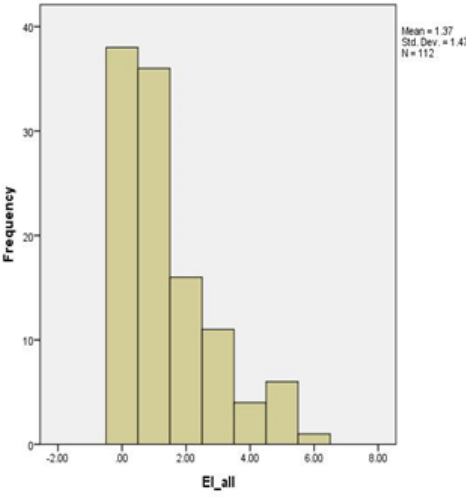

(b)

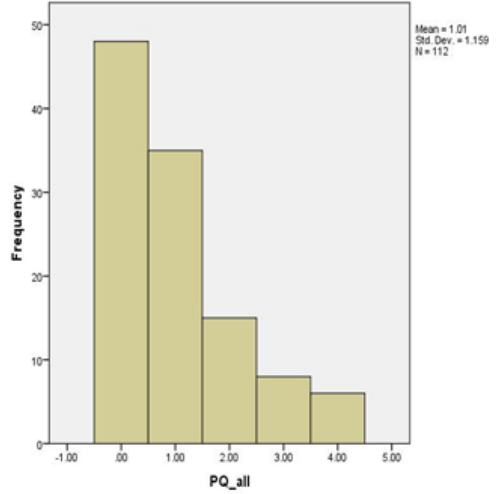

(c)

Figure 4: Histograms showing the number of students who engaged with the three different types of learning activities. (a) shows the engagement with the MCQ activities, with a mean of 5, (b) shows engagement with the EI activities, where almost 40 students did not attempt any of these activities, and (c) shows a similar pattern for the PQ activities. 


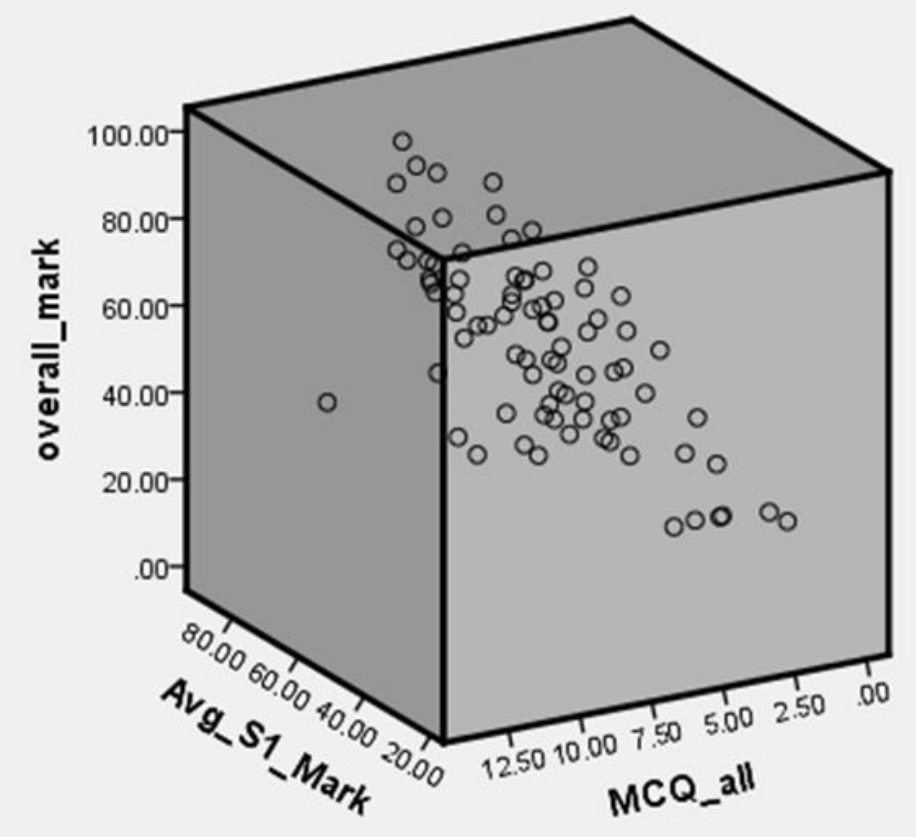

Figure 5: 3D scatterplot showing the effects on the overall mark in year 1 Fluid Mechanics of engagement with the MCQs (MCQ_all) and the overall attainment in prior modules (Avg_S1_Mark). 


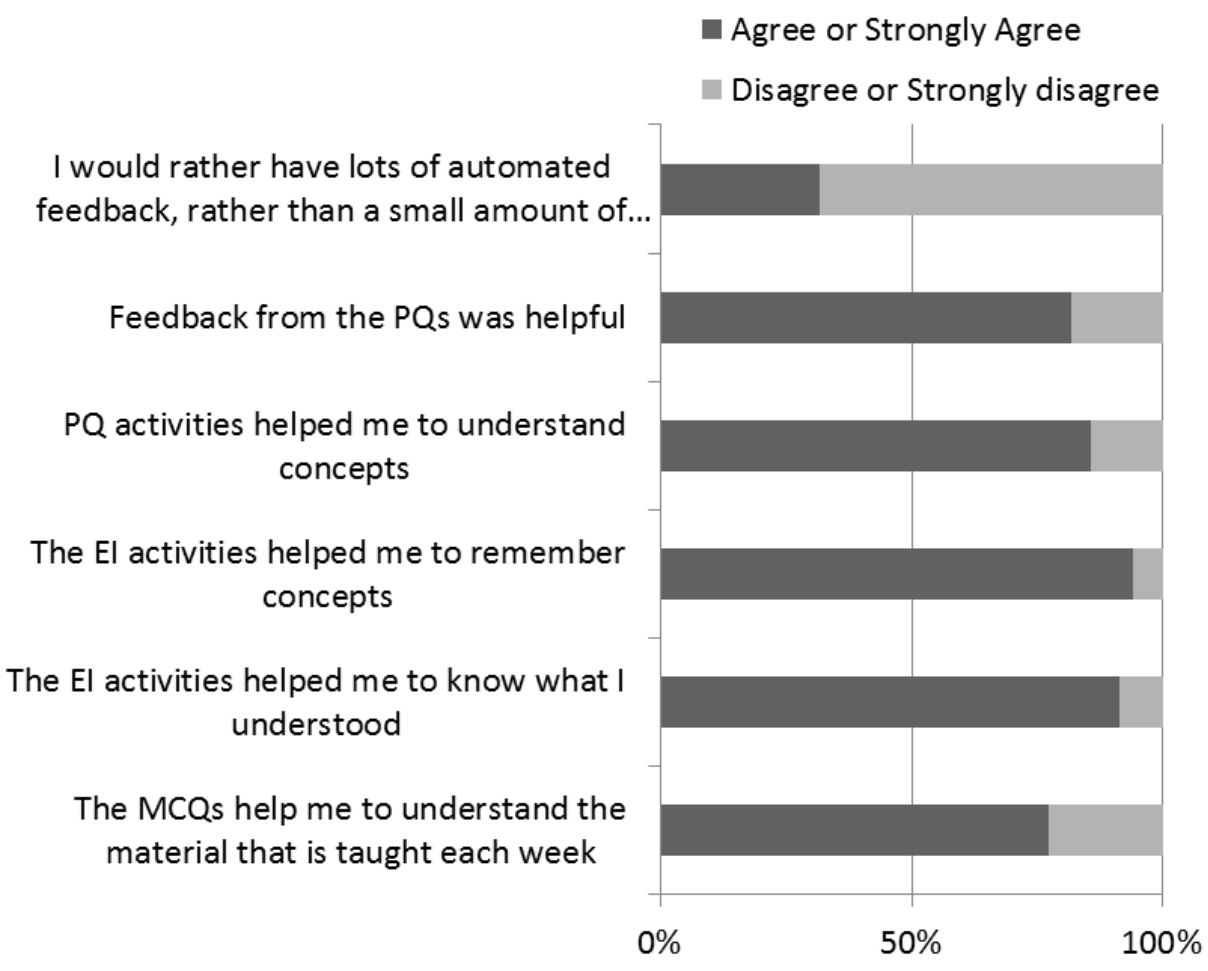

Figure 6: Selected responses to the student experience survey. 